Article

\title{
Cooperation or Localization in European Capacity Markets? A Coalitional Game over Graph Approach
}

\author{
Giorgos Stamtsis *, and Haris Doukas ${ }^{\dagger}$ \\ Decision Support Systems Laboratory, School of Electrical and Computer Engineering, National Technical \\ University of Athens, Iroon Politechniou 9, 15780 Athens, Greece; h_doukas@epu.ntua.gr \\ * Correspondence: stamtsis@gmail.com; Tel.: +30-210-8184625 \\ + The views and opinions expressed in this article are solely those of the authors.
}

Received: 3 May 2018; Accepted: 4 June 2018; Published: 6 June 2018

\begin{abstract}
Capacity markets, as a means to address the capacity adequacy issue, are constantly becoming an important part of the European internal electricity market. The debate focuses on how the capacity markets will be smoothly integrated in one Pan-European power market, without resulting in multiple national fragmentations and consequently in economic efficiency losses. Cross-border participation and regional cooperation are considered as two sine qua non conditions in this respect. The present paper provides a coalitional game theoretical approach aiming to facilitate the cooperation of neighboring countries, when it comes to the security of electricity supply and the necessity of establishing a capacity market. Such an approach can support respective decisions about capacity markets cooperation as well as stress-test the benefits considering all cooperation possibilities.
\end{abstract}

Keywords: cooperation; coalitional games; decision support; capacity market; adequacy; characteristic function; Myerson value; nucleolus; proportional division

\section{Introduction}

During the last years, a key issue in electricity market design debate was whether Energy-Only-Markets (EOM) are able to provide the capacity adequacy levels needed or this is only feasible through Capacity-Energy Markets (CEM) by introducing various Capacity Remuneration Mechanisms (CRM) along with the energy and ancillary services markets [1-8].

European countries have a long track record in designing and operating CRMs in their electricity markets [9-11]. However, the European Commission (EC) is concerned that uncoordinated national approaches regarding the implementation of CRMs will distort the completion of a well-designed and well-functioning Internal Energy Market (IEM). Therefore, EC has launched in April 2015 a sector inquiry to investigate the impact of CRMs planned and implemented in eleven EU member states. The final report [12] of this sector inquiry has been published in November 2016 and recognized that there is a number of regulatory and market failures that can lead to security of supply concerns. According to EC's position, CRMs should be considered as an answer when the adequacy problem persists, even after undertaken corrective actions.

Policy makers and officials from European institutions and energy bodies seem to agree that cross-border participation and regional cooperation is the most efficient way to deal with the main concerns related with the adoption of CRMs, i.e., market fragmentation and less intensive decarbonisation. Indeed, both EC's sector inquiry report and the new draft Electricity Regulation [13] require that market-wide CRM shall be open to participation of capacity providers located outside of the CRM country. Moreover, the draft Regulation foresees that Regional Operational Centres (ROCs) - a future form of cooperation and action coordination between neighbouring Transmission 
System Operators (TSOs) —-will be responsible for calculating the available capacity for cross-border participation in each region. The European Network of Transmission System Operators for Electricity (ENTSO-E), in [14], provides a bit different view regarding regional cooperation, considering the existing and emerging Regional Security Coordinators (RSC) as entities that only assist TSOs and won't be transformed into entities armed with decisive responsibilities. In any case, ENTSO-E has already started publishing the annual Mid-Term Adequacy Forecast (MAF) which, according to the draft Regulation, is considered to serve as the main Pan-European probabilistic methodology-based tool to identify adequacy issues in EU countries and thus paving the way for the possible introduction of a capacity market or any other type of CRM.

But by just applying the common EU rules when it comes to the implementation of a CRM is not sufficient to secure market efficiency. If the national authorities insist to follow in the future a national path regarding security of supply, then this will result in a more conservative approach, with higher figures of available capacity needed for Europe as a whole, as well as increased cost for consumers and emissions.

On the contrary, regional cooperation can build on the fact of non-simultaneously scarcity events i.e., relatively lower simultaneous peak demand, and on a lower percentage for the regional reserve margin requirement. Tackling the adequacy question at regional level can avoid market distortions and keep down costs and consumer prices $[15,16]$. The issue of regional coordination is investigated in [17], while two different types of barriers i.e., mistrust regarding the actual implementation of the European Security of Supply legislation and short-term allocation of transmission rights according to EU's Target Model are identified and some realistic answers are provided in [18].

To the best of our knowledge, it is the first time that coalitional games over graph are used in the present paper in order to support the decision making about capacity markets cooperation. Additionally, we provide an approximation of an initial reasonable range of cooperation when countries start thinking about common efforts towards capacity adequacy.

The rest of the paper is organized as follows: Section 2 illustrates some basic classes of coalitional games and provides the characteristic function for coalitional games with disjoint but connected components as well as some solution concepts for coalitional games over graphs. Section 3 formalizes the coalitional games over graphs for capacity markets. In Section 4, coalitional games over graph are applied in order to investigate countries cooperation for capacity markets in the area of Southeast Europe while Section 5 discusses the results of this application. Finally, Section 6 concludes the paper and discusses future research topics.

\section{Coalitional Games over Graph; Terminology and Solution Concepts}

Coalitional games is the research field where players are able to contact each other, form coalitions and thus to secure a higher payoff in comparison to the amount that each player could secure if standing alone $[19,20]$. Any coalitional game $\Gamma(N, v)$ consists of the set of the $N$ players $N=\{1,2, \ldots, n\}$ and the characteristic function $v$. The characteristic function allocates to each coalition $S$, with $S \subseteq N$, a real value that equals the maximum payoff the coalition's members can safeguard irrespective of what the rest $N-S$ players of the game do. By definition the characteristic value of the empty coalition is $v(\varnothing)=0$.

A coalitional game is called superadditive if the following condition holds:

$$
v(S \cup T) \geq v(S)+v(T), \forall S, T \subseteq N, \text { if } S \cap T=\varnothing
$$

In Equation (1) indicates that the total payoff of a union of two disjoint coalitions is at least equal to the sum of payoffs that each coalition can safeguard standing alone.

A coalitional game is monotonic if:

$$
v(S) \leq v(T), \quad \text { if } S \subseteq T
$$


i.e., the larger the coalition the larger the savings it can achieve.

A coalitional game is called convex if the following condition holds:

$$
v(S \cup T)+v(S \cap T) \geq v(S)+v(T), \forall S, T \subseteq N
$$

Equation (3) can be rewritten in the following form:

$$
v(S \cup\{i\})-v(S) \leq v(T \cup\{i\})-v(T), \forall S \subseteq T \subseteq N-\{i\}, \forall i \in N
$$

Equation (4) states that in convex games there is always an incentive for a player $i$ to join a larger coalition since this results in a larger increase to the coalition's characteristic value.

If there are no restrictions, all possible coalitions $S$, with $S \subseteq N$, are able to form. However, in the presence of communication or other type of restrictions between the players only connected coalitions would be assigned a value. Disconnected coalitions would be either non-admissible or be assigned a value equal to the sum of the values of their disjoint but connected components [21-23]. If the players can interact only through specific routes, then such coalitional games can be represented with undirected graphs $G=(V, E)$ where $V$ are the vertices-players and $E$ the edges-communication routes of the graph. The present paper builds on the assumption that disconnected coalitions are still admissible and they can secure the value of their connected components. Hence, if $C(G)$ is the set of all connected subgraphs of $G$, then the value of each coalition $S$ in a game over graph $G$ is:

$$
v_{G}(S)=\left\{\begin{array}{r}
v(S) \text { if } S \in C(G) \\
\sum_{K_{i} \in K(S)} v\left(K_{i}\right) \text { otherwise }
\end{array}\right.
$$

where $K_{i}$ are the disjoint, connected components of $S$.

\subsection{Solution Concepts for Coalitional Games over Graph}

\subsubsection{Core}

The core is the set of rational payoffs (called imputations), that cannot be improved over any coalition S [24]. Any imputation $\mathbf{y}$ is part of the game's core if the conditions for global and coalitional rationality hold:

$$
\begin{aligned}
& \sum_{i=1}^{n} y_{i}=v(N) \\
& \sum_{i=1}^{n_{S}} y_{i} \geq v(S)
\end{aligned}
$$

If not empty, the core may have infinite imputations.

\subsubsection{Nucleolus}

The nucleolus delivers one single solution to a coalitional game $[25,26]$. The nucleolus, as a payoff vector, makes the unhappiest coalition under it, happier than the unhappiest coalition under any other imputation. For any coalition $S$ its unhappiness under any imputation $\mathbf{y}$ is measured by the excess $e(S)$, where:

$$
e(S)=v(S)-y(S)
$$

Equation (8) states that the higher the difference between the payoffs allocated by $\mathbf{y}$ to the members of $S$ and the value this coalition can safeguard by standing alone, the happier the coalition $S$ is. If the core is not empty then the nucleolus is part of it. 


\subsubsection{Myerson Value}

Actually, the Myerson value [21] is defined as the Shapley value [27] of a game over graph G, where all coalitions are admissible and the characteristic value of each coalition is given by Equation (5). Hence, the Myerson value assigned to a player $i$ is defined through:

$$
M V_{i}=\sum_{S, i \in S} \frac{\left(n_{S}-1\right) !\left(n-n_{S}\right) !}{n !}\left(v_{G}(S)-v_{G}(S-\{i\})\right)
$$

Equation (9) states that player $i$ is allocated the marginal contribution $v_{G}(S)-v_{G}(S-\{i\})$ that it brings to the coalition of the $S-\{i\}$ players when it joins their coalition. The fraction in Equation (9) reflects the probability that player $i$ arrives after the $S-\{i\}$ players have already arrived and before the arrival of the rest $N-S$ players.

\section{Coalitional Games for Capacity Markets}

In EU area, the Energy Union strategy [28], set by the European Commission in 2014, revises the established national approach to energy security of supply demanding a close cooperation between Member States, the Commission and other political and social stakeholders in energy issues.

The benefits of having coordination at European level or even establishing a single Pan-European capacity mechanism are illustrated in [29]. On the other hand, the benefits of enabling the cross-border participation in national capacity mechanisms are presented in [30].

A review of existing capacity mechanisms in Europe is given in [31]. In [32], we provided an approach of using cooperative game theory for capacity markets purposes. The present paper extends that concept to the coalitional games over graph. Moreover, it provides a set of restrictions that should be fulfilled in the framework of the game and a new characteristic function for the coalitional game is derived. Additionally, the present paper examines whether this family of coalitional games over graph holds some basic features such as monotonicity and superadditivity. Furthermore, the present paper adopts the approach of cooperation between directly interconnected countries, which is also reflected in Art. 21 of the new draft Electricity Regulation [13] rather than having cooperation between not directly connected countries, as it is the case in [32]. Relying on a third country increases the risk for the cooperating countries that, at a time of scarcity, the third country may not allow (or reduce the available capacity for) exports. The current European legislative framework permits the reduction or ban of export (as a last resource measure) if security of supply is endangered at national level.

For any two countries $i$ and $j$ that opt to cooperate, the benefits of such coalition depend on the transmission capacity of the interconnection between $i$ and $j$. Additionally, it is reasonable to expect that during the pre-game negotiations, the maximum figure that $i$ can recognize to $j$, and vice-versa, as $j$ 's contribution to $i$ 's capacity adequacy is a fraction of $j$ 's capacity requirement (which is a function of its peak demand). This means that even if $j$ would claim that it can increase its contribution to $i$ 's adequacy up to the transmission capacity of the interconnection between these two entities, country $i$ would not accept this claim using the argument that during a scarcity event taking place in their neighbourhood, $j$ would probably try to safeguard its own security of supply as well. Additionally, player $j$ does not intend to recognize to player $i$ that it would accept, regarding $i$ 's adequacy, a contribution higher than a certain percentage of $i$ 's capacity requirement (which is a function of its peak demand). Actually, the present paper considers that player $i$ could accept at the end of the game a higher percentage of its adequacy being secured by the other players but this cannot apply during the coalition formation phase. These two assumptions are reflected in factor $d$ which we set at $d=20 \%$. Currently, this value for $d$ seems neither conservative nor aggressive since the current goal for interconnections at country level, set by European Commission, is $10 \%$ in 2020 and it is discussed to be increased at $15 \%$ or to be reshaped at $30 \%$ goals in 2030 [33]. Finally, the coalition of $i$ and $j$ has to be able to serve the coalitional capacity requirement (which is a function of the simultaneous peak demand). 
Taking into consideration all these parameters, the present paper defines the coalitional game for capacity adequacy purposes in the following way:

Let $i$ be a country, $D_{i}$ the peak demand in this country and $R_{i}=1.1 D_{i}$ the capacity requirement of this country, assuming a $10 \%$ margin over the peak demand. Let also $T_{j i}$ be the transmission capacity, from $j$ to $i$, between country $i$ and country $j$. To avoid free-rider effect and provide a more level-playing field for the coalition formation, in the rest of this paper we consider that transmission capacity is the same at both directions i.e., $T_{i j}=T_{j i}$ in any case.

Then if $i$ and $j$ opt to form a coalition $S$ so as to commonly establish a capacity market and deal with capacity adequacy issues, then the possible benefits of $i$ and $j$ are:

$$
b(i, j)=\Omega_{i, j}+\Omega_{j, i}
$$

where $\Omega_{i, j}$ is the possible contribution of $j$ to the capacity adequacy of the country $i$ and it is defined as:

$$
\Omega_{i, j}=\min \left(T_{j i}, d \cdot R_{i}, d \cdot R_{j}\right)
$$

Equation (11) states that $j$ 's possible contribution to $i$ equals the transmission capacity from $j$ to $i$ unless the limits related to $j$ 's peak demand and $i$ 's capacity requirement are active. At this point, we have not considered yet the coalitional capacity requirement limitation.

Now, if player $i$ belongs to a coalition $S$ then the possible contribution of the rest $S-\{i\}$ players to $i$ 's adequacy is:

$$
\Omega_{i, S}=\min \left(\sum_{r \in L_{i}} \Omega_{i, r}, d \cdot R_{i}\right)
$$

where and $L_{i}=\left\{l_{i, 1}, \ldots l_{i, g_{i}}\right\}$ is the group of the countries which are directly connected to $i$.

We set the percentage for the coalitional capacity requirement at $5 \%$ (instead of $10 \%$ at national level) recognizing the fact that non simultaneity of forced power plant outages can lead to lower reserve margin requirements in larger groups of countries. Then it is $R_{S}=1.05 D_{S}$ and the general characteristic function of this game is given as:

$$
v(S)=\min \left(\sum_{i \in S} \Omega_{i, S}, \sum_{i \in S} R_{i}-R_{S}\right)
$$

Equation (13) denotes that the value of coalition $S$ is equal to the sum of the benefits accumulated by each country unless these benefits conflict the countries capability to meet the coalitional capacity requirement. In that case, the value of the coalition equals the difference between the sum of all national capacity requirements and the coalitional requirement.

As stated, the present paper studies coalitions which may have disjoint, connected components. Therefore, for this family of games over graph the final value $v_{G}(S)$ of each coalition $S$ is derived by applying Equation (5) along with Equation (13). The coalitional games of capacity markets used in this paper can be further explained by means of the example in Figure 1.

All five countries have peak demand equal to $1500 \mathrm{MW}$ and the transmission capacity of any link at any direction is $300 \mathrm{MW}$. For the coalition $S=\{D, E\}$ we assume a simultaneity peak demand factor of 0.9 .

From (12) it is $\Omega_{D}=\Omega_{E}=300 \mathrm{MW}$. On the other hand, it is $R_{S}=2835 \mathrm{MW}$ and therefore the characteristic value of coalition $S$ is:

$$
v_{G}(S)=v(S)=\min (600,465)=465 \mathrm{MW}
$$


Regarding coalition $T=\{C, D, E\}$, we assume a simultaneity peak demand factor of 0.84 , due to different electricity consumption profiles. It is $\Omega_{C}=\Omega_{E}=300 \mathrm{MW}$ and $\Omega_{D}=330 \mathrm{MW}$. The coalitional capacity requirement is $R_{T}=3969 \mathrm{MW}$ and hence, the characteristic value of the coalition is:

$$
v_{G}(T)=v(T)=\min (930,981)=930 \mathrm{MW}
$$

The first example indicates that the characteristic value of the coalition depends on the coalitional capacity requirement. Actually, it is expected that this would be the most frequent case in this family of coalitional games. However, for coalitions with significant seasonal differences in electricity consumption profiles the restriction imposed by the available transmission capacity could also set the coalition's value.

Finally, regarding coalition $F=\{B, D, E\}$, which has disjoint, connected components, it is:

$$
v_{G}(F)=v(B)+v(D, E)=0+465=465 \mathrm{MW}
$$

Furthermore, we study if this family of coalitional games belongs to some basic classes of coalitional games.

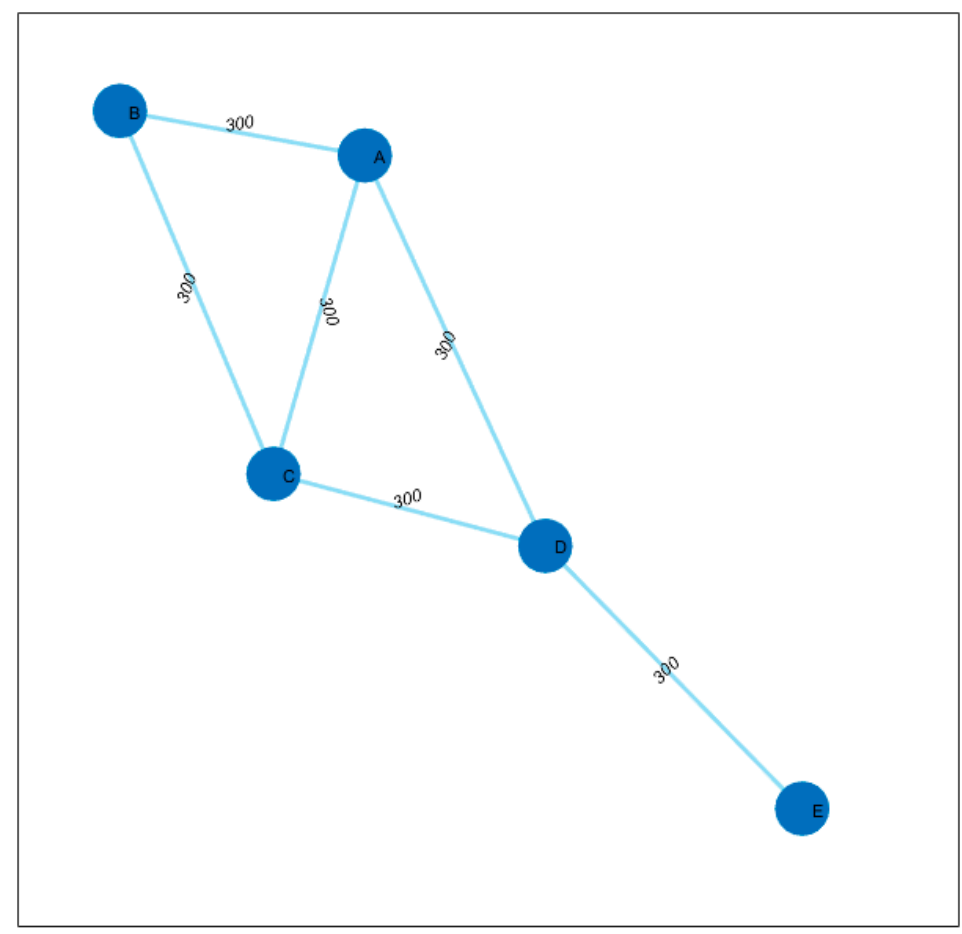

Figure 1. Graph of a 5-country coalitional game.

\subsection{Monotonic}

Any TU coalitional game $\Gamma=(N, v)$ is called monotonic if (2) holds. For the family of coalitional games over graphs, defined by (5) and (13), the worst case, in terms of value increase, is that the groups $S$ and $\{T-S\}$ have same electricity consumption profiles and hence a simultaneity peak demand factor equal to one. In this case it is:

$$
\begin{aligned}
\mathrm{v}(T)=\min \left[\sum_{i \in S} \Omega_{i, S}\right. & +\sum_{j \in\{T-S\}} \Omega_{j,\{T-S\}} \\
& +\left(\sum_{m, n} \Omega_{m, n}: m \text { connected with } n \text { and } m \in S, n\right. \\
& \left.\in\{T-S\}),\left(\sum_{i \in S} R_{i}-R_{S}\right)+\left(\sum_{j \in\{T-S\}} R_{j}-R_{\{T-S\}}\right)\right]
\end{aligned}
$$


The second and third term in the first part of the bracket in (17) as well as the second term in the second part of the bracket are equal or greater than zero hence from (13) and (17) one concludes that $v(T) \geq v(S)$, so (2) holds.

If the coalitions $S$ and $\{T-S\}$ are not connected then it is:

$$
v_{G}(T)=v(S)+v(T-S)
$$

and hence (2) holds again, thus this family of coalitional games is monotonic in any case.

\subsection{Superadditive}

The condition for superadditive coalitional games is already presented in (1). For the disjoint but connected groups $S$ and $T$, and assuming again the worst case of simultaneity factor equal to one for the peak demand, it is:

$$
\begin{aligned}
\mathrm{v}(S \cup T)=\min & {\left[\sum_{i \in S} \Omega_{i, S}\right.} \\
& +\sum_{j \in T} \Omega_{j, T} \\
& +\left(\sum_{m, n} \Omega_{m, n}: m \text { connected with } n \text { and } m \in S, n \in T\right),\left(\sum_{i \in S} R_{i}\right. \\
& \left.\left.-R_{S}\right)+\left(\sum_{j \in T} R_{j}-R_{T}\right)\right] \geq \min \left[\sum_{i \in S} \Omega_{i, S}+\sum_{j \in T} \Omega_{j, T},\left(\sum_{i \in S} R_{i}-R_{S}\right)\right. \\
& \left.+\left(\sum_{j \in T} R_{j}-R_{T}\right)\right] \\
& \geq \min \left[\sum_{i \in S} \Omega_{i, S},\left(\sum_{i \in S} R_{i}-R_{S}\right)\right] \\
& \left.+\min \left[\sum_{j \in T} \Omega_{j, T}\left(\sum_{j \in T} R_{j}-R_{T}\right)\right]=v(S)+T\right)
\end{aligned}
$$

If $S$ and $T$ are not connected then $v_{G}(S \cup T)=v(S)+v(T)$.

Hence, (1) holds in any case and these coalitional games over graph are superadditive as well.

\subsection{Convex}

The condition for a game to be called convex is presented in Equations (3) and (4).

For the game presented in Figure 1, assuming simultaneity factor for peak demand equal to 0.9 for any coalition, it is:

$$
v(D \cup E)-v(D)=465-0=465>v(\{C, D\} \cup E)-v(C, D)=697.5-465=232.5 \mathrm{MW}
$$

Hence, the coalitional games for capacity adequacy are not always convex. Actually, although monotonicity is obvious for these games, convexity is rather difficult to hold because of the networks topology and the coalitional capacity requirements.

\section{Coalitional Games over Graph in Southeast Europe}

This session provides examples of the coalitional games over graph, defined by (5) and (13), in the area of Southeast Europe (SEE). The countries in SEE region are estimated to install an additional 14 GW-27 GW of power generation until 2025 [34]. Ageing power plant fleet, energy and climate targets of EU are the main drivers for the additional generation needed. Cooperation between the neighbouring countries could result in significant savings regarding the amount of generation capacity that these countries would need to have available so as to safeguard the desired level of security of supply. Available capacity is the subset of the installed capacity, which can be mobilized by TSO at any time so as to meet the most stressed situations regarding the operation of the electrical system.

Two group of SEE countries are selected based on the existing Regional Security Coordinators (RSC) [14]. Of course, other initial arrangements between countries regarding cooperation could 
also be possible. The rationality of our choice is linked to the fact that the TSOs, of the countries participating in each RSC, have already a given record of cooperation regarding coordinated transfer capacity calculation, common grid model, short-term adequacy forecast, operational planning security analysis and coordination of outage planning. The first group consists of Bosnia-Herzegovina $(B A)$, Serbia (RS), and Montenegro $(M E)$, so for the 3-country game it is $N=\{B A, R S, M E\}$. The second group of countries is Bulgaria $(B G)$, Greece $(G R)$, Former Yugoslav Republic of Macedonia $(M K)$ and Albania $(A L)$ and the 4-country game is $N=\{B G, G R, M K, A L\}$. Country abbreviations used in the present paper are in line with ISO 3166-1 (adopted by United Nations as well). The extended area of Southeast Europe is illustrated in Figure 2. The two initial groups of countries are illustrated with yellow (3-country game) and blue (4-country game) colour. Additionally, Table 1 provides the transfer capacity data (for adequacy purposes) of the region's interconnections. These data are obtained from the Excel files accompanying the 2016 edition of the Mid-Term Adequacy Forecast of ENTSO-E [35]. For each interconnection we have used the minimum transmission capacity for both directions so as to avoid any free-rider effect. For any of the following games, factor $d$ has been set at $20 \%$.

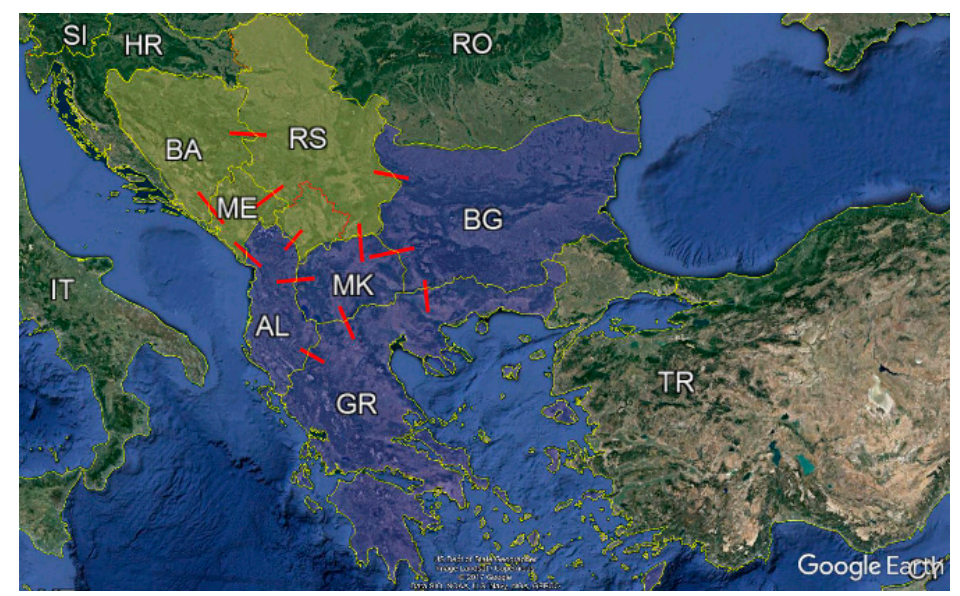

Figure 2. Southeast Europe region with electricity interconnections.

Table 1. Transmission capacities on Southeast Europe interconnections (in MW), year 2020.

\begin{tabular}{cccccccc}
\hline From/To & BA & RS & ME & BG & GR & MK & AL \\
\hline BA & & 600 & 400 & & & & \\
RS & 600 & & 500 & 200 & & 650 & 330 \\
ME & 400 & 500 & & & & & 350 \\
BG & & 200 & & & 400 & 100 & \\
GR & & & & 400 & & 850 & 250 \\
MK & & 650 & & 100 & 850 & & 200 \\
AL & & 330 & 350 & & 250 & 200 & \\
\hline
\end{tabular}

\subsection{The 3-Country Game}

For the 3-country game with $N=\{B A, R S, M E\}$, peak demand with reference to year 2020 is obtained from [35]. The peak demand data along with the capacity requirement and coalition characteristic values for the 3-player game are given in Table 2. The second column illustrates the countries which are members of each coalition while the third column provides the peak demand of each coalition. For the single-country coalitions the peak demand equals the peak demand of each country as obtained from the excel files in [35]. For the multiple-country coalitions the peak demand is derived as the maximum value of the vector consisting of the 8760 sums of the hourly demand of the countries which belong to that coalition. Hourly demand data for each country are again provided in the excel files in [35]. The fourth column depicts the capacity requirement of each 
coalition. For the single-country coalitions the capacity requirements equals 1.10 of the coalition's peak demand while for the multiple-country coalitions the capacity requirement equals 1.05 of the coalition's peak demand. The fifth column illustrates the sum of the possible benefits for all countries participating in each coalition. These benefits are derived through Equations (10)-(12). The sixth column reflects the restriction of meeting the capacity requirement of each coalition, as given in Equation (13). This restriction states that the savings, that each coalition can safeguard, cannot be higher than the difference between the sum of the capacity requirement of the countries participating in that coalition and the capacity requirement of the coalition itself. In other words, the available capacity needed in the coalition's area cannot be reduced, through the countries' cooperation, beyond the point that equals the coalitional capacity requirement. Finally, the seventh column depicts the characteristic value of each coalition. According to Equation (13) this value is the minimum of the values provided in the fifth and sixth column respectively. Table 2 depicts that the savings of the grand coalition $N$ is $659 \mathrm{MW}$, i.e., if these three countries choose to cooperate they would need safeguarding $659 \mathrm{MW}$ less available capacity in comparison to the sum of the available capacities needed if each country would choose to stand alone.

The next step is to allocate this savings to the three countries participating in this game. For this 3-country game, due to network topology, all seven possible coalitions include only connected components, thus in this case Myerson value is identical with Shapley value, as can be seen from Equations (5) and (9). The nucleolus and Shapley value solutions for the 3-country game are presented in Table 3 while the core of the game and the placement of nucleolus and Shapley value are drawn in Figure 3. The area of the triangle encompasses all rational solutions (imputations) and each point of this triangle has barycentric coordinates which equal the savings allocated to each country according to the solution represented by this point. The sum of the barycentric coordinates of each point is fixed and equal to the savings of the grand coalition, i.e., 659. For example, for the countries $\{B A, R S, M E\}$ the barycentric coordinates of the triangle's vertices are $[659,0,0],[0,659,0]$ and $[0,0,659]$, respectively. The core is the area of the imputations that hold the global and coalitional rationality (see Equations (6) and (7)). As can be seen in Figure 3, the Shapley value is off the core for this game while nucleolus is, by definition, within the core.

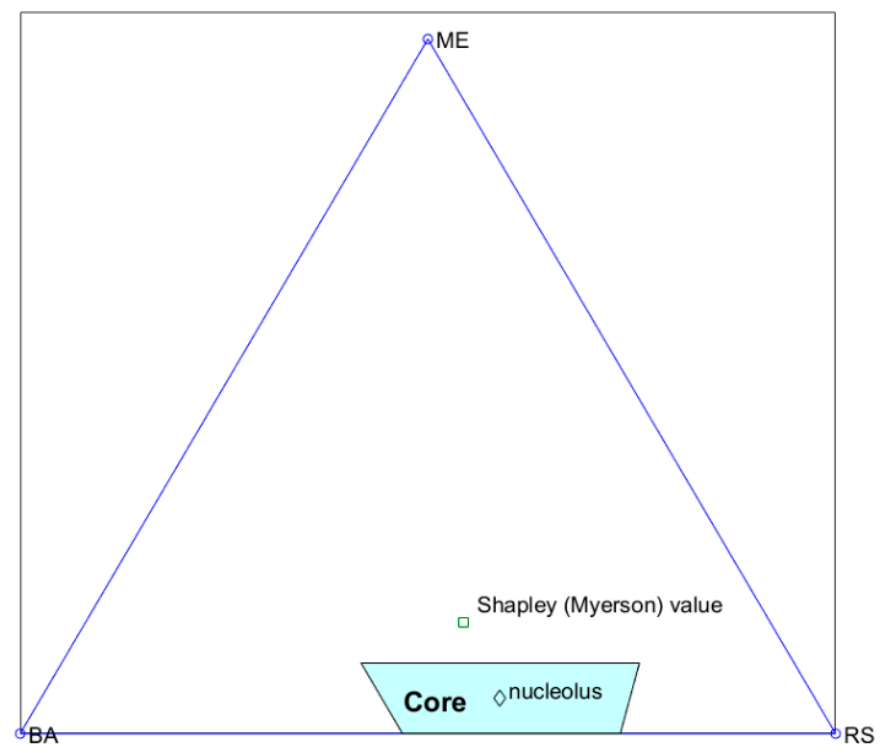

Figure 3. The core, Shapley (Myerson) value and nucleolus of the 3-country game. 
Table 2. Data and characteristic values for the 3-country game (in MW).

\begin{tabular}{rcccccc}
\hline & S & Peak Demand & Capacity Requirement & $\sum_{i \in S} \Omega_{i, S}$ & $\sum_{i \in S} R_{i}-R_{S}$ & $v_{G}(S)=v(S)$ \\
\hline 1 & BA & 2522 & 2774 & 0 & 0 & 0 \\
2 & RS & 7121 & 7833 & 0 & 0 & 0 \\
3 & ME & 703 & 773 & 0 & 0 & 0 \\
4 & BA, RS & 9538 & 10,015 & 1100 & 592 & 592 \\
5 & BA, ME & 3196 & 3356 & 309 & 192 & 192 \\
6 & RS, ME & 7784 & 8173 & 309 & 433 & 309 \\
7 & BA, RS, ME & 10,211 & 10,722 & 1419 & 659 & 659 \\
\hline
\end{tabular}

Table 3. Solutions for the 3-country game (in MW).

\begin{tabular}{cccc}
\hline & Country & Shapley (Myerson) Value & Nucleolus \\
\hline 1 & BA & 247.4 & 254.2 \\
2 & RS & 305.8 & 371.3 \\
3 & ME & 105.8 & 33.5 \\
& $N=\{$ BA, RS, ME $\}$ & 659.0 & 659.0 \\
\hline
\end{tabular}

\subsection{The 4-Country Game}

For the 4-country game with $N=\{B G, G R, M K, A L\}$, Table 4, similarly to Table 2 of the 3-country game, provides the data for the peak demand and the capacity requirement of each coalition. It also provides, in fifth and sixth column, the possible benefits of each coalition as well as the numerical value of the restriction imposed by the need to meet the capacity requirement of each coalition. Finally, Table 4 depicts the characteristic value that each coalition can safeguard for its members.

Due to the network topology, there is one coalition in this 4-country game which consists of disjoint components. More specifically, the coalition $\{B G, A L\}$ consists of the two disjoint components $\{B G\}$ and $\{A L\}$. In this case, each component consists of a single country, so there is no need to check if the countries of each component are connected with each other. According to Equation (5) the characteristic value of this coalition equals the sum of the characteristic value of each component. This procedure is depicted in the row number 7 of Table 4. Of course, the final characteristic value of this coalition is equal to zero because each disjoint component consists of a single country and thus, the value that each component can safeguard is zero. Again, we remind that all data for the 4-country game are derived from the excel files in [35]. As can be seen, the savings that the grand coalition $N=\{B G, G R, M K, A L\}$ can safeguard to its members is $2366 \mathrm{MW}$.

Apart of the two game theoretical solutions, we have applied an additional solution for this 4-country game i.e., the proportional division (pd) rule where the grand coalition's savings are allocated to its members proportionally to their capacity requirement. This is a simpler, more straightforward solution which could be used if coalitional games are not considered (see for example [29]). 
Table 4. Data and characteristic values for the 4-country game (in MW).

\begin{tabular}{|c|c|c|c|c|c|c|c|}
\hline & $s$ & Peak Demand & Capacity Requirement & $\sum_{i \in S} \boldsymbol{\Omega}_{i, S}$ & $\sum_{i \in S} R_{i}-R_{S}$ & $v_{G}(S)$ & \\
\hline 1 & BG & 7159 & 7875 & 0 & 0 & 0 & \\
\hline 2 & GR & 10,415 & 11,457 & 0 & 0 & 0 & \\
\hline 3 & MK & 1849 & 2034 & 0 & 0 & 0 & \\
\hline 4 & $\mathrm{AL}$ & 1830 & 2013 & 0 & 0 & 0 & \\
\hline 5 & BG, GR & 16,072 & 16,876 & 800 & 2455 & 800 & \\
\hline 6 & BG, MK & 8889 & 9333 & 200 & 576 & 200 & \\
\hline \multirow[b]{2}{*}{7} & \multirow[b]{2}{*}{$\mathrm{BG}, \mathrm{AL}$} & 7159 & 0 & 0 & 0 & $\mathbf{v}\left(\mathbf{K}_{\mathbf{1}}\right)=\mathbf{0}$ & \multirow[b]{2}{*}{0} \\
\hline & & 1830 & 0 & 0 & 0 & $\mathbf{v}\left(\mathbf{K}_{2}\right)=\mathbf{0}$ & \\
\hline 8 & GR, MK & 11,511 & 12,087 & 814 & 1403 & 814 & \\
\hline 9 & GR, AL & 11,447 & 12,019 & 500 & 1451 & 500 & \\
\hline 10 & $\mathrm{MK}, \mathrm{AL}$ & 3649 & 3831 & 400 & 216 & 216 & \\
\hline 11 & BG, GR, MK & 17,641 & 18,523 & 1714 & 2842 & 1714 & \\
\hline 12 & $\mathrm{BG}, \mathrm{GR}, \mathrm{AL}$ & 17,719 & 18,605 & 1300 & 2739 & 1300 & \\
\hline 13 & $\mathrm{BG}, \mathrm{MK}, \mathrm{AL}$ & 10,679 & 11,213 & 600 & 709 & 600 & \\
\hline 14 & GR, MK, AL & 12,544 & 13,171 & 1466 & 2332 & 1466 & \\
\hline 15 & BG, GR, MK, AL & 19,283 & 20,247 & 2366 & 3131 & 2366 & \\
\hline
\end{tabular}

Table 5 illustrates the savings allocated to each country according to the three different solution schemes used for this game. Finally, Figure 4, which has been drawn by incorporating some additional elements from the toolbox in [36], provides an illustration of the 4-country game where the regular tetrahedron encompasses all rational solutions (imputations) of the game while the light-blue painted area denotes the core of the game. As can be seen, all three solutions are located within the core of the game.

Table 5. Solutions for the 4-country game (in MW).

\begin{tabular}{ccccc}
\hline & Country & Myerson Value & Nucleolus & pd \\
\hline 1 & BG & 482.1 & 450 & 797.0 \\
2 & GR & 956.4 & 1057 & 1159.5 \\
3 & MK & 575.6 & 533.0 & 205.8 \\
4 & AL & 351.9 & 326.0 & 203.7 \\
& $N=\{\mathrm{BG}, \mathrm{GR}, \mathrm{MK}, \mathrm{AL}\}$ & 2366.0 & 2366.0 & 2366.0 \\
\hline
\end{tabular}

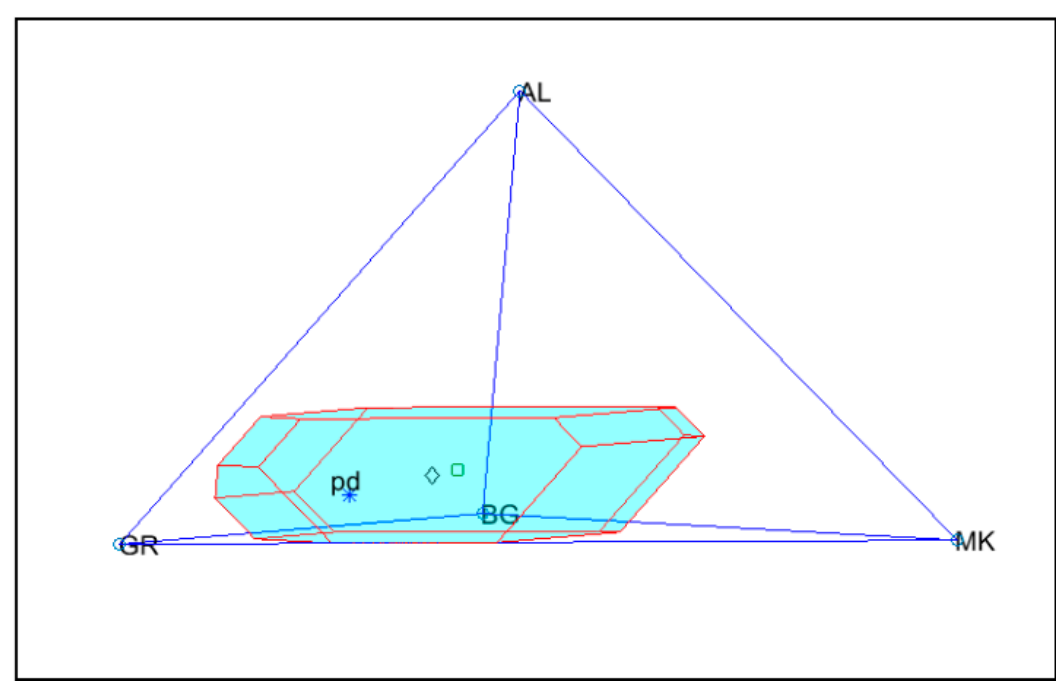

Figure 4. The core, Myerson value, nucleolus and proportional division of the 4-country game. 
By measuring the excess of the unhappiest coalition we can determine which one of the three methods provides the relatively less robust solution. We remind that, according to Equation (8), a smaller excess indicates a happier coalition because the excess measures the difference between what the coalition can safeguard by itself and what a specific solution vector assigns to this coalition. As can be seen in Figure 5 (see the arrows in the upper right area), the proportional division rule provides the relatively less robust solution. Indeed, the excess of the unhappiest coalition, according to Equation (8), under Myerson value, nucleolus and proportional division is $-300.1 \mathrm{MW},-326.0 \mathrm{MW}$ and $-103.0 \mathrm{MW}$ respectively.

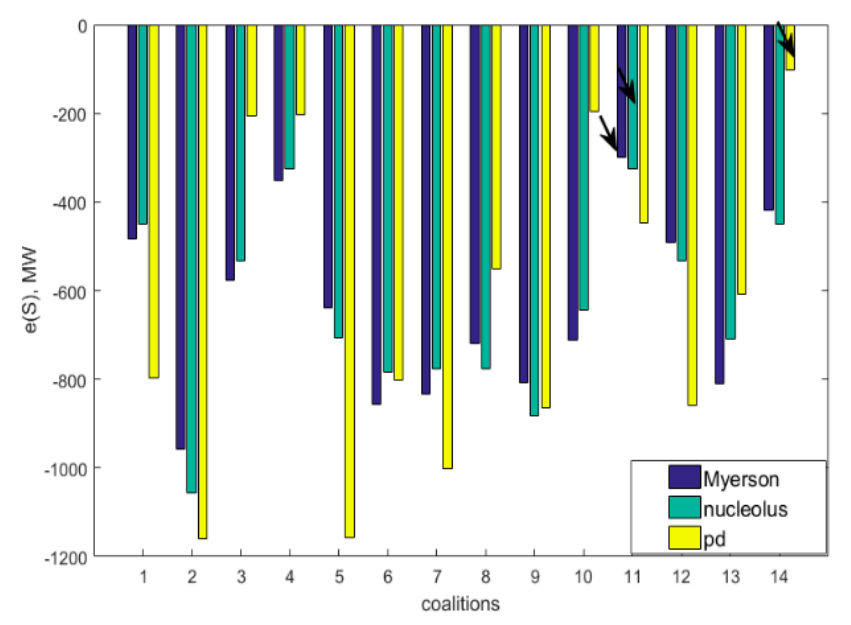

Figure 5. Coalitions' excess and the unhappiest coalition (arrow) under the three payoff vectors.

\subsection{The 7-Country Game}

Once enough experience is gained by RSC's member-countries regarding cooperation towards capacity adequacy, the next step could be the national authorities and TSOs to enhance and extend the cooperative regulatory framework making the decision for a larger scale cooperation. This larger scale could denote either a pan-European capacity market, if all countries agree on that, or an extended cooperation between countries belonging to different RSCs and/or regions.

In the present paper, we investigate a larger scale cooperation at regional level. More specifically, we form a 7-country game where the players are the countries participating in the 3-and 4-country games. Thus, the grand coalition of the 7-country game is $N=\{B G, G R, M K, A L, B A, R S, M E\}$.

As expected and can be seen in Table 6, in this new coalitional game over graph the number of coalitions with disjoint, connected components, due to the network topology, is significantly increased. Almost two sevenths of the 7-country game coalitions consist of disjoint, connected components while there was no such case in the 3-country game and just a single one in the 4-country game.

Since this family of games is superadditive, a larger coalition would result in total savings being higher than the sum of savings achieved at RSC level. As can be seen in Table 7 in case all seven countries would opt for a single capacity market, the grand coalition's savings would reach $4024 \mathrm{MW}$, i.e., 999 MW higher savings than the sum of 3-country and 4-country games.

For the 7-country game we again calculate three different solutions, namely the Myerson value, nucleolus and proportional division. The nucleolus of this game is, by definition, within the core while Myerson value and proportional division are off the core. The excess of the unhappiest coalition under Myerson value, nucleolus and proportional division is calculated to be $153.9 \mathrm{MW},-52.1 \mathrm{MW}$ and 436.4 MW respectively. Thus, proportional division rule provides a less robust solution in comparison to the two game theoretical methods. 
Table 6. Coalitions with disjoint, connected components.

\begin{tabular}{ccc}
\hline Game & Number of Coalitions with Disjoint, Connected Components & Total Number of Coalitions \\
\hline 3-country & 0 & 7 \\
4-country & 1 & 15 \\
7-country & 36 & 127 \\
\hline
\end{tabular}

Table 7. Solutions for the 7-country game (in MW).

\begin{tabular}{ccccc}
\hline & Country & Myerson Value & Nucleolus & pd \\
\hline 1 & BG & 544.2 & 350.8 & 911.7 \\
2 & GR & 1278.5 & 1987.9 & 1326.3 \\
3 & MK & 516.0 & 298.8 & 235.5 \\
4 & AL & 406.2 & 196.2 & 233.0 \\
5 & BA & 301.9 & 221.7 & 321.2 \\
6 & RS & 835.9 & 916.1 & 906.8 \\
7 & ME & 141.3 & 52.5 & 89.5 \\
& $N$ & 4024.0 & 4024.0 & 4024.0 \\
\hline
\end{tabular}

\section{Discussion}

The analysis presented in Section 4 reveals some interesting remarks regarding the benefits and restrictions, when the countries decide to cooperate towards capacity adequacy as well as some pros and cons of the three different solutions used in order to allocate the savings. Moreover, such an analysis can provide an indication of the initial range of the cooperation that countries of the Southeast Europe region should aim at.

More specifically, for the 3-country game, Figure 3 makes obvious that the Shapley value is located outside the core's game, thus making it a less robust solution. Actually, coalition $S=\{B A, R S\}$ coalition would prefer to stand alone than accepting Shapley value because $\sum_{i \in S} S V_{i}=552.5<592=v(S)$. As always, the nucleolus of the game is part of the core, thus making it a more robust solution. In this case robustness means that if a solution vector a belongs to the core (and hence Equations (6) and (7) hold) it is not possible to find another solution vector $\mathbf{b}$ which increases the savings allocated to the members of a coalition $S$ without decreasing the savings allocated to the rest $\mathrm{N}-\mathrm{S}$ players of the game. On the other hand, the Shapley value is more contribution-oriented and is calculated in a more transparent way.

Regarding the restrictions activated in the two games at the RSC level, a comparison of Tables 2 and 4 reveals that the characteristic values in the 4-country game are mostly limited by the transmission capacities (which determine the possible benefits that are depicted in the fifth column of Table 4) between these four countries while the most often limit activated in the 3-country game is the coalitional capacity requirement. This remark applies to the grand coalitions in these two games as well. Specifically, Table 4 indicates that there is a large potential of savings, due to significant differentiation in consumption profiles, in the area of the southern Balkan Peninsula, which nevertheless cannot be exploited because of low transmission capacity limits. This is exactly the problem that regional cooperation in the area could deal with. As can be seen in Table 5, the proportional division rule cannot disclose the pivotal role of the two smaller countries of this game, namely $M K$ and $A L$. On the contrary, the two coalitional game theoretical methods recognize the importance of the two countries regarding the formation of and the gains achieved by the grand coalition and both the Myerson value and nucleolus assign to these two countries a higher payoff.

From Table 7 it is obvious that the savings of the 7-country game are essentially larger than the sum of the 3-country and the 4-country games, i.e., $4024-(659+2366)=999 \mathrm{MW}$. In general, when the members of two disjoint coalitions opt to form a larger game, larger savings are to be expected since this family of games is superadditive. However, some countries which had a more pivotal role in the 4-country game, in comparison to their role in the 7-country game, might receive a lower payoff in 
the latter. More specifically, $B G$ and $M K$ would prefer to receive almost any payoff as members of the 4-country game than the payoff assigned to them by the nucleolus vector of the 7-country game. Hence, the Meyrson value seems more suitable to provide the necessary incentives for establishing the grand coalition of the 7-country game. If the rest five countries would not agree with the replacement of nucleolus by Meyrson value then they could opt to leave the 7-country game and form their own 5-country game with $N=\{G R, A L, B A, R S, M E\}$. However, the grand coalition's savings of this 5-country game would be as low as $v(N)=2401 \mathrm{MW}$ while the sum of the payoffs assigned to these five countries in the 7-country game under the Meyrson value is $2963.8 \mathrm{MW}$. Thus, if the five countries would opt to form their own game they would secure $562.8 \mathrm{MW}$ less savings. Therefore, it is beneficial to all neighbouring countries to enter the 7-country game and accept the Meyrson value as the payoff vector. Of course, $M K^{\prime}$ 's payoff under Meyrson value in the 7-country game is slightly lower than in 4-country game but $M K$ alone has not the strength to prohibit the rest six countries from forming a 6-country game since the savings of the grand coalition $N=\{B G, G R, A L, B A, R S, M E\}$ would be $v(N)=3601 \mathrm{MW}$, thus still $576 \mathrm{MW}$ higher than the sum of the savings of the 3- and 4-country games $(2366+659=3025 \mathrm{MW})$.

Based on the superadditivity and the monotonicity of this family of games, the larger the area of the game the higher the total savings achieved. However, larger area means more countries to be involved and, probably, a more complex and/or time-consuming process until a final decision is reached towards the establishing of a common capacity market. In any case, a significant difference between the savings secured at a narrower circle and the ones achieved if the game is played in a larger area may provide an adequate boost so as to overcome, within a relatively short time, any complexity issues.

Actually, this is the case of the 7-country game where the union of the two initial RSCs regions has provided a significant increase of the savings [ $4024-(2366+659)=999 \mathrm{MW}$ or $33 \%$ increase]. Of course, it is not guaranteed that any increase of the game's area would result in such impressive increase of the total savings. Actually, since the game, as defined in (5) and (13), is not convex, and the contributions to a country's adequacy are dependent on its interconnections' capacity, as shown in (11)-(13), it could be expected that once a critical mass of countries join the game at regional level the further enlargement would probably have limited impact on the relative savings. Table 8 depicts exactly that claim in the 7-country game, showing that the percentage of the benefits tends to be saturated, once a critical mass of countries has entered the game.

Table 8. Benefits of selected coalitions in SEE area.

\begin{tabular}{cccc}
\hline Coalition & $\sum \boldsymbol{R}_{\boldsymbol{i}} \mathbf{( M W )}$ & $\boldsymbol{v}_{G}(\boldsymbol{S})(\mathbf{M W})$ & $\boldsymbol{v}_{G}(S) / \sum \boldsymbol{R}_{\boldsymbol{i}}$ \\
\hline BA, RS, ME & 11,381 & 659 & $5.8 \%$ \\
BG, BA, RS, ME & 19,256 & 1176 & $9.4 \%$ \\
BG, GR, MK, AL & 23,378 & 2366 & $10.1 \%$ \\
BG, GR, MK, AL, RS & 31,211 & 3503 & $11.2 \%$ \\
BG, GR, MK, AL, BA, RS, ME & 34,759 & 4024 & $11.6 \%$ \\
\hline
\end{tabular}

Of course, the number of the countries that could result in this plateau depends on the network topology and the differences in the consumption profiles in each region of Europe. Moreover, it should be noted that other RSCs in Europe already cover more extended geographical areas. Thus, for other European regions the initial cooperation towards capacity adequacy could start by involving a significant higher number of countries without facing additional complexity issues.

Based on the problem formulated and the results presented and analysed in this paper, a main finding is that using coalitional game theory and its solution concepts, when it comes to cooperation towards capacity market, can efficiently support the decision making process by offering trade-offs between robustness, transparency and calculation simplicity. The second finding is that the countries should take advantage of the existing cooperation platforms i.e., the Regional Security Coordinators 
and then aim to increase the cooperation area until the trade-off between the savings achieved and the complexity of procedures required will be balanced.

\section{Conclusions}

Capacity adequacy issues can be addressed through regional or continental capacity markets in order to achieve economic efficiency. The present paper defines the characteristic function of coalitional games over graph for a capacity market with multiple-country participation and studies some basic characteristics of this family of games, i.e., monotonicity, superadditivity, etc. This coalitional game is superadditive, thus increasing the area of the game results in increase of the benefits in terms of absolute value. However, the relative benefits might reach a plateau when a critical mass of countries have already entered the game. Additional increase of the game area should always be weighed against the possible increase of complexity in the decision making process regarding the establishment and the operation of the common capacity market.

The approach presented in this paper can support respective decisions about capacity markets cooperation as well as stress-test the benefits considering all cooperation possibilities. Coalitional games over graph could be used in the area of Southeast Europe in order to address the issue of the capacity renewal and expansion needed, during the next decade, in the most efficient way. Cooperation is, initially, modelled at the level of the existing Regional Security Coordinators and then expanded to a 7-country game through the union of the two RSC areas. Thus, the potential of the interconnections and the different consumption profiles, especially between Greece and the other countries, is captured at a larger extent and it is then efficiently allocated.

Future work will extend the research to coalitional games over graph with non-admissible coalitions and over larger regions. Of course, the main question of how to establish the appropriate political and regulatory framework which can facilitate the regional cooperation for capacity adequacy purposes could only be investigated and answered through an interdisciplinary research work.

Author Contributions: Giorgos Stamtsis conceived the paper scope and the theoretical framework and co-wrote the paper. Haris Doukas co-wrote the paper, analyzed the results and designed the results and discussion sections.

Funding: This research received no external funding.

Conflicts of Interest: The authors declare no conflict of interest.

\section{References}

1. Joskow, P. Capacity payments in imperfect electricity markets: Need and design. Utilities Police 2008, 16, 159-170. [CrossRef]

2. Chattopadhyay, D.; Alpcan, T. Capacity and Energy-Only Markets under High Renewable Penetration. IEEE Trans. Power Syst. 2016, 31, 1692-1702. [CrossRef]

3. Spees, K.; Newell, S.A.; Pfeifenberger, J.P. Capacity Markets-Lessons Learned from the First Decade. Econ. Energy Environ. Policy 2013, 2, 1-26. [CrossRef]

4. Bhagwat, P.C.; Iychettira, K.; Richstein, J.C.; Chappin, E.J.L.; De Vries, L. The effectiveness of capacity markets in the presence of a high portfolio share of renewable energy sources. Utilities Policy 2017, 48, 76-91. [CrossRef]

5. Cramton, P.; Ockenfels, A. Economics and design of capacity markets for the power sector. Zeitschrift für die Energiewirtschaft 2012, 36, 113-134. [CrossRef]

6. Höschle, H.; De Jonghe, C.; Six, D.; Belmans, R. Capacity Remuneration Mechanisms and the Transition to low-carbon Power Systems. In Proceedings of the 12th International Conference on the European Energy Market (EEM15), Lisbon, Portugal, 20-22 May 2015.

7. Traber, T. Capacity Mechanisms on Central European Electricity Markets: Effects on Consumers, Producers and Technologies Until 2033; Discussion Paper 1385; Deutsches Institut für Wirtschaftsforschung (DIW): Berlin, Germany, 2014. 
8. Ollila, J. Nordic Energy Co-Operation: Strong Today—Stronger Tomorrow. Nordisk Ministerråd: Denmark, 2017; p. 31. Available online: https://norden.diva-portal.org/smash/get/diva2:1106010/FULLTEXT01.pdf (accessed on 30 April 2018).

9. Süßenbacher, W.; Schwaiger, M.; Stigler, H. Kapazitätsmärkte und-Mechanismen im Internationalen Kontext. In Proceedings of the 7th International Energiewirtschaftstagung an der TU Wien 2011, Vienna, Austria, 16-18 February 2011.

10. Hancher, L.; De Hauteclocque, A.; Sadowska, M. (Eds.) Capacity Mechanisms in the EU Energy Market; Oxford University Press: Oxford, UK, 2015; ISBN 978-0-19-874925-7.

11. European Commission. Final Report of the Sector Inquiry on Capacity Mechanisms. Staff Working Document SWD (2016) 385 Final, pp. 50-67. Available online: http://ec.europa.eu/competition/sectors/energy/ capacity_mechanism_swd_en.pdf (accessed on 30 April 2018).

12. European Commission. Final Report of the Sector Inquiry on Capacity Mechanisms. COM (2016) 752 Final. Available online: http:/ / ec.europa.eu/competition/sectors/energy / capacity_mechanisms_final_report_ en.pdf (accessed on 30 April 2018).

13. European Commission. Proposal for a Regulation of the European Parliament and of the Council on the Internal Market for Electricity. COM (2016) 861. Available online: http:/ / eur-lex.europa.eu/resource. html?uri=cellar:9b9d9035-fa9e-11e6-8a35-01aa75ed71a1.0012.02/DOC_1\&format=PDF (accessed on 30 April 2018).

14. ENTSO-E. Regional Cooperation and Governance in the Electricity Sector. Available online: https://www.entsoe. eu/Documents/Publications/Position\%20papers\%20and\%20reports/entsoe_pp_regions_1604_web.pdf (accessed on 30 April 2018).

15. Cepeda, M.; Finon, D. Generation capacity adequacy in interdependent electricity markets. Energy Policy 2011, 39, 3128-3143. [CrossRef]

16. Tao, L.; Schwaegerl, C.; Gaxiola, E.; Mueller, H. A pan-european capacity market prospect analysis based on IRENE-40 scenarios. In Proceedings of the 22nd International Conference on Electricity Distribution CIRED 2013, Stockholm, Sweden, 10-13 June 2013.

17. Roques, F.; Verhaeghe, C. Different Approaches for Capacity Mechanisms in Europe: Rationale and Potential for Coordination? In Capacity Mechanisms in the EU Energy Market; Hancher, L., De Hauteclocque, A., Sadowska, M., Eds.; Oxford University Press: Oxford, UK, 2015; pp. 79-94, ISBN 978-0-19-874925-7.

18. Mastropietro, P.; Rodilla, P.; Batlle, C. National capacity mechanisms in the European internal energy market: Opening the doors to neighbours. Energy Policy 2015, 82, 38-47. [CrossRef]

19. Osborne, M.J.; Rubinstein, A. A Course in Game Theory; Electronic Version, 2012-9-24; MIT Press: Cambridge MA, USA, 1994; pp. 255-298, ISBN 0-262-65040-1.

20. Peleg, B.; Sudhölter, P. Introduction to the Theory of Cooperative Games; Springer: Berlin, Germany, 2007; ISBN 978-3-540-72944-0.

21. Myerson, R.B. Graphs and cooperation in games. Math. Oper. Res. 1977, 2, 225-229. [CrossRef]

22. Skibski, O.; Michalak, T.P.; Rajwn, T.; Wooldridge, M. Algorithms for the Shapley and Myerson Values in Graph-restricted Games. In Proceedings of the 2014 International Conference on Autonomous Agents and Multi-Agent Systems, Paris, France, 5-9 May 2014; pp. 197-204.

23. Chalkiadakis, G.; Greco, G.; Markakis, E. Characteristic function games with restricted agent interactions: Core-stability and coalitional structures. Artif. Intell. 2016, 232, 76-113. [CrossRef]

24. Gillies, D.B. Solutions to general non-zero-sum games. In Contributions to the Theory of Games; Tucker, A.W., Luce, D.R., Eds.; Princeton University Press: Princeton, NJ, USA, 1959; Volume IV, pp. 47-85, ISBN 978-0691079370.

25. Schmeidler, D. The nucleolus of a characteristic function game. SIAM J. Appl. Math. 1969, 17, 1163-1170. [CrossRef]

26. Bjørndal, E. Cost Allocation Problems in Network and Production Settings. Ph.D. Thesis, Norwegian School of Economics and Business Administration, Bergen, Norway, 2002; pp. 123-171. Available online: https://brage.bibsys.no/xmlui/bitstream/handle/11250/164214/Bjorndal_2002.pdf?sequence= 1\&isAllowed=y (accessed on 30 April 2018).

27. Shapley, L.S. A value for n-person games. In Contributions to the Theory of Games II, Annals of Mathematics Study 28; Kuhn, H.W., Tucker, A.W., Eds.; Princeton University Press: Princeton, NJ, USA, 1953; pp. 307-317, ISBN 978-0691079356. 
28. European Commission. Third Report on the State of the Energy Union. COM (2017) 688. Available online: https: / / ec.europa.eu/commission/publications/third-report-state-energy-union-annexes_en (accessed on 30 April 2018).

29. Bucksteeg, M.; Spiecker, S.; Weber, C. Impact of Coordinated Capacity Mechanisms on the European Power Market. HEMF Working Paper 01/2017. Available online: https://papers.ssrn.com/sol3/papers.cfm? abstract_id=2896686 (accessed on 30 April 2018).

30. Tennbakk, B.; Capros, P.; Höschle, H.; Åsmund, J.; Wolst, J.; Zampara, M. Framework for Cross-Border Participation in Capacity Mechanisms. Report for the European Commission. 2016, pp. 116-131. Available online: https: / / ec.europa.eu/energy / sites/ener/files / documents / cross-border_crm_study_-_final_report_ __170106.pdf (accessed on 30 April 2018).

31. Stamtsis, G.; Lychnaras, V. Integration of Capacity Markets into the European Electricity Market. In Proceedings of the DEMSEE 2015 Conference, Budapest, Hungary, 24-25 September 2015.

32. Stamtsis, G.; Lychnaras, V. Cooperative Game Theory Solutions in Regional European Capacity Markets. In Proceedings of the DEMSEE 2016 Conference, Heraklion, Greece, 22-23 September 2016.

33. European Commission. Towards a Sustainable and Integrated Europe. Report of the Commission Expert Group on Electricity Interconnection Targets. Available online: https: / /ec.europa.eu/energy /en/topics / projects-common-interest/electricity-interconnection-targets/expert-group-electricity-interconnectiontargets (accessed on 30 April 2018).

34. Vujasinovic, Z. SEE electric power systems. Generation, consumption, exchanges \& transmission forecasts Until 2025. In Proceedings of the Enlargement and Integration Action Workshop, Vienna, Austria, 15 December 2015; Available online: http:/ / publications.jrc.ec.europa.eu/repository/bitstream/JRC102982/vienna\%20workshop\% 20scenarios\%20see\%2015-12-15_final.pdf (accessed on 30 April 2018).

35. ENTSO-E. Mid-Term Adequacy Forecast 2016, Dataset. Available online: https://www.entsoe.eu/outlooks / midterm/ (accessed on 30 April 2018).

36. Calvo, M.; Ángel, M.; Sánchez Rodríguez, E. TUGlab: A Cooperative Game Theory Toolbox. University of Vigo, Spain, 2005. Available online: http:/ / mmiras.webs.uvigo.es/TUGlab/ (accessed on 30 April 2018).

(C) 2018 by the authors. Licensee MDPI, Basel, Switzerland. This article is an open access article distributed under the terms and conditions of the Creative Commons Attribution (CC BY) license (http:/ / creativecommons.org/licenses/by/4.0/). 